\title{
Migration as a Complex Phenomena of Identity and Social Integration: A Sociological View on Albanian Migration Case
}

\author{
PhD. Cand. Matilda Likaj Shaqiri \\ Department of Educational Sciences, Faculty of Educational \& Philology \\ Bedër University, Tirana, Albania \\ e-mail: matildalikaj@gmail.com
}

\section{Doi:10.5901/ajis.2013.v2n9p613}

\begin{abstract}
The end of communism regime and the raise of democratization process helped Albanian society to be 'open border' toward all countries in the world, especially toward Western ones during 1990's. This phenoma was quite new for Albanian society. Migration involves a series of events that can be highly traumatizing of identity and problems of inegration. The process involves uprooting, being separated from traditional values, being placed in new social and cultural different situations of hosted countries. So for many migrants, social integration process is not quite easy. Resistance to their participation in society results from language problems and culturally defined behavior that often reinforce stereotypes and prejudices. This situation brought out many challenges in the social identity and integration problems of migrants life in hosted countries. In this paper it is going to be focused on the analyses of Albanian migration during post communist period. Also it will be focused on the recent Albanian migration, emigrants and their integration process in the hosted European societies. Consequently to this, it is going to be focuse on the challenges of their social identity during the integration period. Are the emigrants integrated and harmonizing with the European societies or they are just trying to shape their life according to the social, economical and cultural conditions? Or let say that, are the emigrant assimilating their own identity just to be a social actor in the European societies?
\end{abstract}

Keywords: Migration; Identity; Social Inegration; Albanian Migration Case

\section{Introduction}

Migration process is as old as the world is, but unfortunatly not all sides of migration phenomenas are recently detailed study in Albanian social sciences. According to Vullnetari, Albanian emigration after 1990's presents a unique case not only in post-communist Europe, but also more widely, by reason of its massive concentration over a short period of time and its specific features. 'Van Hear has described it as 'a new migration order', King considers Albania a 'laboratory for the study of migration and devel-opment', while Carletto, Davis, Stampini and Zezza talk about a 'country on the move' (Vullnetari, 20). Consequently to this, it is neccesary to claim that migration is as important as a complex phenomena in the post communist Albanian society.

The flow of Albanian migration was expended as a huge flood toward different states of the world, but especially toward European countries. The main policy focus of European Union is on managing inward migration, governments may also restrict internal movements and outward migration. But it was not same situation in early 1990's with Albanian migration. Because Albanian migration situation faced as exodus and was quite different form other migration floods. The literature on migration remains very much state-centred, focused on developed countries and on economic development (especially in European Countries), with little attention to social development and integration issues. Consequently we can say that Gwendoyln and Thielemann stressed that migrants, a common distinction is made between legal and illegal migrants, the former entering their new host country through a legal route (such as a temporary or permanent immigrant visa or a work permit), the latter often being associated with illegal human trafficking and have difficulties on integration in host countries. It is often overlooked that a substantial number of so-called illegal migrants entered their new country legally, but lost their legal status by overstaying their visa (Sasse \&Thielemann; 656). The social consequences of the increasing ethnic-cultural diversity of industrialized societies, and more specific the recent upsurge in immigrant influx to European societies( Hooghe ; Trappers; Meuleman; \& Reeskens; 504)

This situation causes social identity anomies of migrants. Also, here it is very important to mention that remittances can have a huge economical development impact on sending societies ( Haan; 63). Remittances from overseas workers add up to more than US\$100 billion a year. About US $\$ 60$ billion goes to developing countries, exceeding funds from all 
overseas development assistance (Jolly \& Bridge; 26). This means that migration phenomena plays an important role to the economies of sending and host societies too. Because, is very important to say that emigration play a very important role not just for reorganization of life, but for society's cultural, social, economical and political perspective. So the migration phenomena seems to be very complex in its form but so simple in idea of migrant to migrate. Not just because of different social, cultural, economical and political reasons but also from the imporatance and multi dimensions of migration flow can be identified as complex migration phenomena. So related to these reasons, sometimes the Albanian migrants have been discriminated but they are the most integrated migrants in European countries.

Migration involves a series of events that can be highly traumatizing of identity and problems of inegration. The process involves uprooting, being separated from traditional values, being placed in new social and cultural different situations of hosted countries. So for many migrants, social integration process is not quite easy. Most of the time integration broughts out social and cultural indentities problems. Resistance to their participation in society results from language problems and culturally defined behavior that often reinforce stereotypes and prejudices. This situation brought out many challenges in the social identity and integration problems of migrants life in hosted countries.

While ethnic-cultural diversity and social cohesion are not necessarily irreconcilable across Europe, policy makers might nevertheless be interested in ways to strengthen the social fabric of diversity societies. In this respect, it needs to be remembered that across the industrialized societies, national governments have adopted a wide range of policies aiming at the integration of the newcomers into their host (Brubaker; 96). And indeed, studies have already demonstrated that integration policies have an impact on the incorporation of immigrants into society (Fennema \& Tillie; 54)

This paper contains the focus on the explanation of migration phenomena as an importamt issue in social sciences. Also in this paper is going to be analyze social integration and dilemas of social identity of migrants in hosted societies. And as the sample of migration as a complex phenomena and the social identities facing at migrants it is going to analyze on the the Albanian migrants situation at European countries.

\section{Migration as a Complex Phenonema}

Migration is a very complex phenomena in the perspective of socio-cultural and economic life. Human migration is the movement of people from one country to another for the purpose of taking up permanent or semi permanent residence, usually across a political boundary. For thousands of years people have migrate to search for food, survive conquer frontiers, colonize new territories, escape from war zone or political authorities and look for new and more rewarding and existing opportunities. People can either choose to move or voluntary migration and be forced to move or involuntary migration. According to a widely used definition, migrants are persons who have been outside their country of birth or citizenship for a long period of time and stay there for different reasons. On the migrant side, one can usefully distinguish three main groups: economic, forced and family migrants, which is a distinction based on the motivations for leaving one's country of origin. According to me, migrants could not be classified on just three groups because there are so many people who are not forced to migrate but they want to leave their countries for political reason (such as political transition), for education and for a better socio-cultural activities. Joly and Reeves said that migration is often cast as a "problem" to "control" in the domestic politics of richer countries, heightened by recent concerns with "national security" (Engle; 25).

Also in social sciences, the term 'migrant' spread an underlying definitional imprecision that blurs the respective fields of study, socio-cultural and policy-making as well as the linkages between these. So we can claim that migration is the moving of people internally within countries, or internationally between countries from sending to receiving countries. This moving may be for the short or long term, for economic, political, cultural or social reasons. It may be regular/legal or irregular/illegal. Migration all over the world is the excepted as documented or undocumented people movement, which are effected by political incorporation, economics, politics or historical associations. But unfortunately the prevailing approach of national policymakers is accordingly one of managing the flow of migrants (Lucas; 71) driven by domestic concerns rather than more global interests or the interests and rights of migrants. The intergovernmental body, the International Organization for Migration (IOM), works under the banner of 'Managing migration for the benefit of all' and has gained significant support from governments (Jolly \& Bridge; 29). Ravenstein saw migration as an inseparable part of development, and he asserted that the major causes of migration were economic. Migration patterns were further assumed to be influenced by factors such as distance and population densities. According to Hein people are expected to move from low income to high income areas, and from densely to sparsely populated areas, that is, the general notion that migration movements tend towards a certain spatial-economic equilibrium, has remained alive in the work of many demographers, geographers, and economists ever since and, as we will see, is also the underlying assumption of 
push-pull theories (Hein; 4). Hans de Hein's point of view about migration is related to the neo classical theory. But it is important to claim that Neo-classical migration theory could not able to deal with Albanian migration case because the factors that push people to emigrate were not just economic, but an opportunity to escape from Albania, to discover the 'magic' of other countries and 'new' hope for the future.

Different theories of migration (such as Push and Pull Theory; Neo-Classical Equilibrium theory; Historical Structural Theory; Transnational Migration Theory etc), which mainly focus on the causes of migration and the feedback mechanisms through which population movements, are perpetuated. So the causes and consequences of migration are strongly interrelated, and part of the same general processes of social and economic transformation, the circumstances that cause migration will equally affect migration on development in sending societies. For this reason we can say that migration phenomena's complexity can be seen also to definitions above. And the complexity is multidimensional and varies according to each migration flood/wave of a country.

The scholarly debate has tended to separate the developmental determinants and effects or impacts of migration artificially from more general processes of social including economic change. There is a clear need to study migration impacts in their wider societal context, and to see how migration as: A process which is an integral part of broader transformation processes embodied in the term "development"; but also has its internal, self-sustaining and selfundermining dynamics; and impacts on such transformation processes in its own right (Hein; 2). So, is very important to say that emigration play a very important role not just for reorganization of life, but for society's cultural, social, economical and political perspective.

The complexity of migration trends in the twenty-first century cannot be ignored. In the past, most migrants came from countries with colonial and specific bilateral arrangements to European and other economical development countries. But the migration profile has been changed during the last decade. There has been a rapid increase in the diversity of migrants as a result of a more interconnected world, with continued economic disparities. The increase in the number of sending countries has resulted in a new 'super-diversity' in Europe, with many disparate communities composed of small groups made up of many different nationalities. So consequently to this we can claim the other face of complexity of migration phenomena. The flow of migrants to Europe has also become more complex in terms of movement and legal status. After the fall of communism and the opening of borders of Albanian state, another factor affected the rise of migrations flows. This factor was and still is globalization. Globalization is changing the nature of the migration journey.

According to Hans de Hein, one-way voyages to a new country of settlement, the type of migration which populated the New World, are giving way to more temporary and flexible movements, and a new generation of migrant globetrotters. With cheaper communication and travel, migrants have greater opportunities to maintain links with their homecountries, and 'return' and 'circular' migration is becoming increasingly commonplace. In Europe particularly, an increasing proportion of the migrant population is 'transnational: that is to say, people working in one country while maintaining a family and social life in another (Hein; 26). According to this perspective is very evident and important to say that the problematic form of migration is reflected to the social relation of one society. So migration is very benefit for the economical conditions but its reflection or symptoms causes the social anomies for receive and hosted societies too. This phenomenon is seen in social identities of migrants, such as they have e feeling of not belonging in the hosted society but even in their own state. So this feeling is mostly related with integration according to policies of receive countries and sometimes this application may not be totally voluntary.

Migration phenomena's complexity derives from a number of factors. According to Vullnetari these factors may include origin or destination country perspectives, macro or micro analyses, discipline based approaches, concerns over short or long term impacts, varying types of migration and development spatially and over time and, not least, various ways of measuring the two. Increasing interdependencies of social, economic and political aspects require an approach that takes these global interdependencies into account, but also embeds the analysis in a specific social and geo-historical context relevant to the study (Vullnetari; 35). So as conclusion of this part we can say that social; cultural and even the personal identity of migrants must be fit or involvement of migrants, and their families, in the social, cultural political and econimical life of the host country's conditions. Most of the time these conditions are phrased as social integration of migrants in hosted societies. Migrants may not be complain voluntraty to these conditions. From this point started to be faced the complexity of migration phenomena.

\section{Social Integration and Dilemas of Social Identity of Migrants}

The concept 'integration' is used form social researches in migration field to refer to the degree of involvement of migrants, and their families, in the social, cultural political and econimical life of the host country. In everyday langyage 
sometimes the word 'integration' is confused by assimilation. But integration does not mean assimilation. Nor does it imply that integration requires adjustment only on the side of migrants. 'The term 'integration' and not 'assimilation' is to emphasize respect for and incorporation of differences and the need for mutual adaptation. 'Integration' also reflects an appreciation of diversity instead of the homogenity that 'assimilation' has come to connote' (Fix; 50). Despite some reservation about the word integration the adopts of it are about the discussion because of its wide international usage, the role of quality services in achieving both social inclusion and the successful management of migration. Also Gray claimed that integration is adopted then, with some reservation about the word, as a goal of a migration policy that involves the management of immigration and immigrant settlement. There is an implication that integration is about participation or involvement which takes place to a certain degree (Gray; 131).

From another point of view integration as term, in everyday meaning is variable and highly indeterminate. Is important to stress that its meaning differ according to the pervasivenessin policy in public discourse and menaings that are given from research scholars. 'Since it is the root metaphor in terms of which successful migrant insertion into 'host' societis is imagined 'integration' will here be understoood to refer not only to the kind of social positioning/incorporation which an individual migrant might achieve but also and more fundamentally, to specific ways of understanding the social cohesion of the host society' (Zammit; 170).

At the same time, integration does not mean that emigrants must sever ties to their countries of birth nor abandon their cultures, traditions, values, and identities. For most newcomers, the initial focus upon arrival will be on adoubtion to the host society social life. But sometimes facing the social and economical realities formidable barriers to integration of many migrant. According to Durkheim this is called as the proceess of integration. Proccess of integration of migrant is related with social solidarity and social cohesion of hosted societies. So integration is a process that takes time and not all time is successfull for both migrants and hosted societies too. But does this happen same to the migrant to the European societies? Here is important to focuse on the Albanian migrants in Greece, where most of them had to change even their muslim names into orthodoxies one.

Integration may be defined as a two-way process where new migrants and the hosted societies members have responsibility for wellbeing and social cohesion of society. This procees require change on both migrants and receiving community, because integration is a dynamic giving and taking process that takes place over time. In responding to migrants' needs, host societies are unlikely to be able to provide the ideal level of support, constrained by different factors. This factors can be listed as limited economical resources, community need, integration policies, education policies, willing to be integrated on the hosted societies etc. So the migrants have to deal with rooted set of existing values and norms, must accept learning different language, cultural values, traditions and norms, and must accept the different race and ethnicity. For the members of hosted countries they need to accept diveristy of migrants for helping social solidarity and cohesion of society. Because the migrant must bear the integration to the society and it will help social solidarity of hosted society.So the process of migrants' integration depends on the shift in the host societies' attitudes towards them. Consequently to this situation it transforms the social cohesion by creating a new on from both newcomers and receivers. So migration integration proccess is not simple and most of the time is accompained with different social anomies and identity problems. Migrant integration is a complex concept that is fundamentally tied with debates about the migrants' role ine the sender and hosted societies.

According to social sciences are many factors that contribute to the integration of migrants in hosted societies. But british scholars defined five key factors that contribute to the integration proccess of migrants.

Figure 1: Factors that Contribute to Migrants Integration:

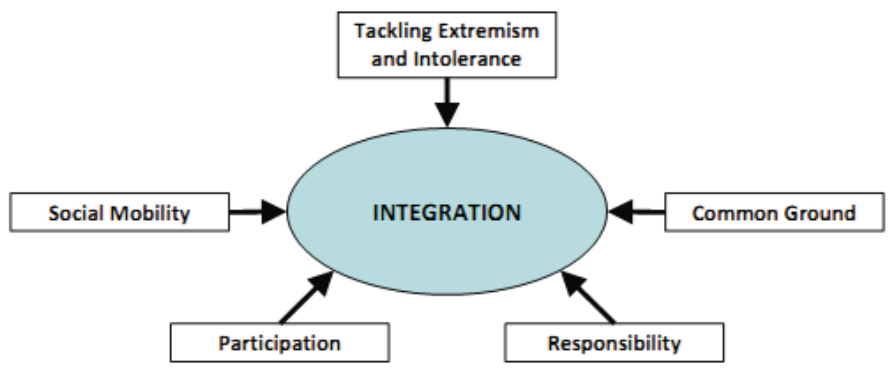

Source: (Policy Team;4) 
So migrants have to participate in the society social, cultural and political activities. Also they have to have the responsibilities of being the receive societies members. These will match the social mobility of member of receive society and migrants. But form both parts (migrants and the receive society's members) tackling extremism and intolerance will not get the integration of migrants integration. According to Migrant Integration Framework Identities are six strategic pathways though which migrants and receive societies collaborate to facilitate migration integration. These pathways can be listed as language and education, economic mobility, equal treatments and opportunity, cultural and social interaction, civic participation and citizenship etc. These pathways serve both as a tool for facilitating integration. These pathways form the dynamic of integration process. Here is very important to stress that general determinants of migrants integration are receive state polices. There must exist social contracts between political system of a state and migrants. $\mathrm{O}$ one hand the success of integration will conduct with entry rules, membership rules and set entire for integration process. In other hand process of migrant integration must appear several patterns such as language, culture, identity and citizenships of migrants. These patterns form the integration continuum and sometimes non-incorporation. From this issue migrants can face the identity dilemmas. In the following part of this paper we are going to be focus on details about the migrants' social integration by taking into consideration Albanian migration case.

\section{Migration and the complexity of social integration in EU: Albanian Migration Case}

The fall of communism in Albania after 1990's and the raise of democratization bring out opportunities of forming relations of Albania with different countries of the world. The end of communism and democratization process helps Albanian society to be 'open border' toward the different countries, especially to European ones. This was the most useful opportunity to run out of Albania for many people. This phenomena first was called as the exodus and later as migration floods. Also we have to claim that this phenoma was quite new for Albanian society. During the post communist period in Albania, people migration has been 'voluntary obbliged' from many factors such as political, cultural and economical transition. Because of these factors, it is not wrong to say that this type of migration has been as voluntary as involuntary. There are different factors that push and pull people to migration to different countries especially to European societies. The fall of communism and the change of political regime, there were brought out the very huge lacks in economical budget, low incomes a high rate of unemployment and the abounded of the industry, farms (ferm), cooperation (koperative) and all factories. The economic situation at that time had all the signs of a crisis, the unemployment rate were raising rapidly and "rapid migration" favored the emigration of people of different social classes. Exiting of the lack of policies to encourage and discourage too, illegal (a lot) and legal (less) immigration include informing and assisting potential emigrants with regard to legal migration opportunities, as well as encouraging decentralized cooperation between the local authorities of inter border areas.. According to Iconomy, Albania, after 21 years (according to the study of the World Bank shows that the number of migrants abroad Albania is around 860,485 persons, or about $27.5 \%$ of the population) (Ikonomi; 15) are still facing with some migration problems, but there are form policies for bringing social control over the migration and its situations. But according to data from MOLSAEO, there were nearly 750,000 and 1.1 million Albanian migrants living abroad in 1999 and 2005, respectively. The majority of them lived in Greece and Italy (Vullnetari; 15). NID reported that the Albanian migrants' number is 1.7 million in 2010 (NID; 8). So we can say the number of Albanian migrants in different countries in the world is so high.

Figure 2: Estimates of Albanians living Abroad, 1999, 2005 and 2010

\begin{tabular}{lrrrrrr}
\hline Country & 1999 & $\%$ & 2005 & $\%$ & \multicolumn{1}{c}{2010} & $\%$ \\
\hline Greece & 500,000 & 67.3 & 600,000 & 54.9 & 750,000 & 44.0 \\
Italy & 200,000 & 27.0 & 250,000 & 22.9 & 450,000 & 26.4 \\
US & 12,000 & 1.6 & 150,000 & 13.7 & 400,000 & 23.5 \\
UK & 5,000 & 0.7 & 50,000 & 4.6 & 50,000 & 2.9 \\
Germany & 12,000 & 1.6 & 15,000 & 1.4 & 15,000 & 0.9 \\
Canada & 5,000 & 0.7 & 11,500 & 1.0 & 15,500 & 0.9 \\
Belgium & 2,500 & 0.3 & 5,000 & 0.5 & 5,000 & 0.3 \\
Turkey & 1,000 & 0.1 & 5,000 & 0.5 & 5,000 & 0.3 \\
France & 2,000 & 0.3 & 2,000 & 0.2 & 10,000 & 0.6 \\
Austria & 2,000 & 0.3 & 2,000 & 0.2 & 2,500 & 0.2 \\
Switzerland & 1,000 & 0.1 & 1,500 & $<0.1$ & 1,500 & $<0.1$ \\
Netherlands & $\mathrm{n.a}$. & $\mathrm{n.a}$ & 1,000 & $<0.1$ & 1,000 & $<0.1$ \\
TOTAL & 742,500 & 100 & $1,093,000$ & 100 & $1,705,500$ & 100 \\
\hline
\end{tabular}

Source: (Vullnetari; 71) 
Albanian migration seems to be as a lake of opportunities and challenges not just for migrants but also for the Albanian society too. Selecting the destination for migrating is related to push and pull factors such as ease of finding work, geographical proximity, ease of entry into the host country, relatives who live in places where they migrate, recognizing the opportunities for education and improvement of professional skills, opportunity to work in their profession and better salaries compared to other countries (Ikonomi, 13). So as we see form the above figure (see figure 2) Albanian migrants had as a target to migrate toward Grecee and Italy. The migration and integration policies in this countries were quite different form each other. Greece applied Robert Park Model of integration that is based on the assimilation and homogenization proccess. The migrant integration policies in Greece were focused on the changing in norms, culture, language and identity (especially religion identity). Greece applied as France nationhood policies for cultural assimilation too. These policies were good just for receiving countries stabilization but not for Albanian migrants. These formed the risk and the complexity of social identities to migrant. Also the stigmatization processes of identity make second generation to feel as the member of any society. Discriminations, misunderstanding, social conflict est. were caused because of formation of these 'difference' between migrants and Greek citizenships. These caused the anomic situation of integration and social identity of migrants.

Another place where Albanian migrants' number is so high is Italy. We can say that Albanian migrants in Italy want to integrate more than Albanian migrants in Greece. This has been caused because the migration policies were based on the Cultural Pluralist Model. This model is based on the application of more tolerance of culture of origin countries of migrants, integration of migrant in receive countries and also ignore the idea of separation. So policies encouraged the maintained of difference of language (for Albanian migrants has been noted that the foreign language has never been an element for not being integrated, because Albanian migrants learn the language of host countries very fast), in culture and religion. These policies made possible Albanian migrants to be more integrated on the Italy.

Nowadays migration and minority policy issues are at the forefront of the political debate in Europe. This make denote a dynamic and rapidly changing set of sensitive political, economic and social issues that affect domestic and international policy-making. According to Menz, for all the good one of these domestic policies is to encourage open borders and free movement, the political calculation on these issues seems to reflect a different rationale. As we know the EU is founded on the four freedoms" of capital, goods, services and people. The last of the freedoms, people, was employed in order to expedite the first three (G. Menz; 742). European integration has led to an increasing role for the $\mathrm{EU}$ in the development of immigration policy. But is important to stress that Western European societies are facing a major social and political challenge in the question of managing the integration of old and new immigrants. The warning signs that we have been failing to cope successfully with this challenge have been visible in many events of recent years (Bounfino; Byrne; Collet; Cruddas; Cuperus; Dijselbleom; Dublet; Einaudi; Hillebrand; Kronig; Pearson; Sik;Ibanez; 35).

Consequently we massively underestimated to what extent ideological, political and cultural changes in the regions where the migrants came from would spill over into our own countries and affect community relations here (Bounfino; Byrne; Collet; Cruddas; Cuperus; Dijselbleom; Dublet; Einaudi; Hillebrand; Kronig; Pearson; Sik; Ibanez; 36). Here is important to stress the Albanian migrants situation in Greece, Germany, England etc. Where the religion identities must be convert into the Christian religion and to change names into the Christians one. But we have to claim that also for Albanian migrants this situation was not so important, because as the lack of religion identy for many than 45 years brought possibility on faciliating the identity changes. But in nowaday Albania, this manner of integration of migrant must be review again.

On the other hand is important to stress too that European integration has led to an increasing role for the EU in the development of migration policy. In the area of migrant integration policy, the most important development has been the passage of the EU's Racial Equality Directive (RED) in 2000 (Givens;73). But this application differ form one state to another. It is very important to say that integration of Albania to European Union is bringing new reconstruction of migration process. According to Brody, the process of migration integration appears to follow one of several patterns. Each of these patterns of integration confronts the issues of culture, language, identity and citizenship in entirely different ways and can be envisioned as lying on a continuum with assimilation falling on one end of the 'integration continuum' and 'non-incorporation' or separation falling at the opposite end (Brody; 20). The integration of migration within a host country is facing with the 'integration continuum' which is the process of assimilation and the acculturation of society. This process brings the challenges to the migrant's identity's anomies. For this reason, during all times migrants were challenging with the stigmatization or being optimize on the front stage of everyday life. Their most faced challenge is discrimination on their own ethnicity (such as Albanian migrants in Greece, Farnce, Germany etc). Another challenge of Albanian migration is the impact on the domestic and foreign policies of our country and host country. In our country, there are lacks of migrant participation on the political process, for example the participation in voting process. For this reason occurs a reorganization of policies on the attracting of Albanian migrant to participate during the voting process. 
But after the candidation for membership in European Union the Albanian migration flows and migrant consciences have been changed. Because there are formed new policies towards the decrease of discrimination in host country and also in home countries are formed strong policies to protect the Albanian emigrants. 'Migrant workers enjoy equal treatment with nationals of the host countries for working conditions, payment of social security, union membership, regardless of nationality, race, sex and Religion' ( Për Emigrimin E Shtetasve Shqiptarë Për Motive Punësimi, Ligj Nr.9668). 'There is a strong link between the European Union integration process and Albanian emigration. This process plays a very important role in the development of policies and priorities in the field of migration. Conditions of Albanian migrants in host countries to guarantee the rights of Albanian citizens abroad and to facilitate the visa application process. Consequently they are considered as priority task of the diplomatic services of the Ministry of Foreign Affairs and Government as a whole' (Ikonomi; 15). that the European Integration has brought out cultural pluralist model toward Albanian migrants, especially after the visa liberalization. These models encourage them to speak and learn Albanian language (open Albanian cultural centers and associations in Italy, Greece etc.), to transmit culture, religion, traditions and customs from one generation to the other. The policies of implication make possible the Albanian migrant identity to be safety and non anomic. This reorganization of migration policies during the European integration give opportunities not just to Albania for forming facilities to Albanian migrant, also give opportunities to European countries policies to be respected and to have a benefical citizenships for sending and receiving countries of migrants.

\section{Conclusion}

Migration involves a series of events that can be highly traumatizing of identity and problems of inegration. The process involves uprooting, being separated from traditional values, being placed in new social and cultural different situations of hosted countries. So for many migrants, social integration process is not quite easy. Most of the time integration broughts out social and cultural indentities problems. Resistance to migrants participation in society results from language problems and culturally defined behavior that often reinforce stereotypes and prejudices. This situation brought out many challenges in the social identity and integration problems of migrants life in hosted countries The end of communism and democratization process helps Albanian society to be 'open border' toward the different countries, especially to European ones. Albanian migrants had as a target to migrate toward Grecee and Italy. The migration and integration policies in this countries were quite different form each other. Also the integration problems of Albanian migrants were prety much in number. Greece applied Robert Park Model of integration that is based on the assimilation and homogenization proccess. The migrant integration policies in Greece were focused on the changing in norms, culture, language and identity (especially religion identity). Greece applied as France nationhood policies for cultural assimilation too. These policies were good just for receiving countries stabilization but not for Albanian migrants. These formed the risk and the complexity of social identities to migrant. Also the stigmatization processes of identity make second generation to feel as the member of any society. Discriminations, misunderstanding, social conflict est. were caused because of formation of these 'difference' between migrants and Greek citizenships. These caused the anomic situation of integration and social identity of migrants.

Another place where Albanian migrants' number is so high is Italy. We can say that Albanian migrants in Italy want to integrate more than Albanian migrants in Greece. This has been caused because the migration policies were based on the Cultural Pluralist Model. This model is based on the application of more tolerance of culture of origin countries of migrants, integration of migrant in receive countries and also ignore the idea of separation. So policies encouraged the maintained of difference of language (for Albanian migrants has been noted that the foreign language has never been an element for not being integrated, because Albanian migrants learn the language of host countries very fast), in culture and religion. These policies made possible Albanian migrants to be more integrated on the Italy.

As we noted that Albanian migrants faced different challenges not just for integration but also for their own social identity. The complexity of integration is related with the social identity anomies that the migrant are facing in received societies. So as conclusion it is important to stress that integration could not be view just form one point of view, but it must be taken migrants into the consideration and the reviews of migration policies.

\section{References}

;(2012). Creating the conditions for integration, Communities and Local Goverment, Policy Team, The National Archives, London 
Bounfino, A.; Byrne, L.; Collet, E.; Cruddas, J.; Cuperus, R.; Dijselbleom, J.; Dublet, F.; Einaudi, L.; Hillebrand, E.; Kronig, J.; Pearson, R.; Sik, E.; Ibanez, C.R.; (2007). Rethinking Immigration and Integration: A New Centre-Left Agenda; Policy Network

Brody,B.(2009), Opening the Door,

De Hein, H.; (2006). Migration Development: A Theoretical Perspective;

Engle, L. (2004). The World In Motion; Short Essays on Migration and Gender, Geneva: International Organization for Migration

Fix, M.; Zimmerman, W. \& Passel, J. (2001). The Integration of Immigrant Families in the United States. Washington, D.C.: Urban Institute

Givens T. E. , (2007). Immigrant Integration In Europe: Empirical Research, Annual Review of Political Sciences

Gray, B., (2006). Migrant Integration Policy: A Nationalist Fantasy of Management and Control? , Translocations: The Irish Migration, Race and Social Transformation Review, Autumn 2006, Volume 1, Issue 1

Ikonomi, L. (2009). E drejta Migratore, Manual trajnues, Editted from World Bank, Migration and Remittances Factbook

NID, (2001), The activity of NID during 1996-2010, National Institute of Diaspora, Albanian Ministry of Foreign Affairs, Tirana

Vullnetari, J. (2012). Albania on the Move: Links between Internal and International Migration; IMISCO Research, Amsterdam University Press

Zammit, D. E. (2007). Migration in the Meditarranean: Equalising Strategies and Social Hierarchies in Migrant Integration; Journal of Mediterranean Studies; Volume 17. No. 2

Lucas, R, (2005). International Migration and Economic Development: Lessons from Low-Income Countries, Edward Elgar Publishing, 2005

Jolly, S \& Bridge, H. R, (2005).Gender and Migration, Overview Report, Institute of Development Studies

Sasse, G\&Thielemann,(2005). E, A Research Agenda for the Study of Migrants and Minorities in Europe JCMS: Volume 43, Number: 4

de Haan, A, (2000). 'Migrants, Livelihoods and Rights: The Relevance of Migration in Development Policies', Social Development Working Paper No: 4, London: Department for International Development,

Menz, G, (2002). Patterns in EU labour immigration policy: national initiatives and European responses, Journal of Ethnic Migration Studies, No: 28(4)

Hooghe, M., Trappers, A., Meuleman, B., \& Reeskens, T. (2008). Migration to European Countries. A Structural Explanation of Patterns, 1980-2004. International Migration Review

Brubaker, R. (1992). Citizenship and Nationhood in France and Germany. Cambridge: Harvard University Press

Fennema, M., \& Tillie, J. (2004). Do Immigrant Policies Matter?Ethnic Civic Communities and Immigrant Policies in Amsterdam, Ličge and Zurich". In R. Penninx 